Research paper

\title{
Sex-specific effects of metformin and liraglutide on renal pathology and expression of connexin 45 and pannexin 1 following long-term high-fat high-sugar diet
}

\author{
Martina Luetić $^{\mathrm{a}}$, Genia Kretzschmar ${ }^{\mathrm{b}}$, Maximilian Grobe ${ }^{\mathrm{b}}$, Leo Jerčić ${ }^{\mathrm{b}}$, Ivana Bota ${ }^{\mathrm{b}}$, \\ Vedrana Ivićc $^{c}$, Marta Balog ${ }^{c}$, Milorad Zjalićc ${ }^{c}$, Marija Vitlov Uljević ${ }^{\mathrm{b}}$, Marija Heffer ${ }^{\mathrm{c}}$, \\ Robert Gaspar $^{\mathrm{d}}$, Tamas Tabi ${ }^{\mathrm{e}}$, Katarina Vukojević ${ }^{\mathrm{b}, \mathrm{f}}$, Sandor G. Vari ${ }^{\mathrm{g}}$, Natalija Filipović ${ }^{\mathrm{b}, *}$

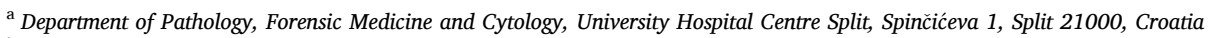 \\ ${ }^{\mathrm{b}}$ University of Split School of Medicine, Laboratory for Neurocardiology, Department of Anatomy, Histology and Embryology, Šoltanska 2, Split 21000, Croatia \\ ${ }^{\mathrm{c}}$ Faculty of Medicine Osijek Josip Juraj Strossmayer University of Osijek, Cara Hadrijana 10/E, Osijek 31000, Croatia \\ ${ }^{\mathrm{d}}$ Department of Pharmacology and Pharmacotherapy, Interdisciplinary Excellence Centre, University of Szeged, Dóm tér. 12., H-6720 Szeged, Hungary \\ e Department of Pharmacodynamics, Faculty of Pharmacy, Semmelweis University, Budapest, Hungary \\ ${ }^{\mathrm{f}}$ University of Split School of Medicine, Laboratory for Early Human Development, Department of Anatomy, Histology and Embryology, Šltanska 2, Split 21000, Croatia \\ ${ }^{\mathrm{g}}$ International Research and Innovation in Medicine Program, Cedars-Sinai Medical Center, Los Angeles, CA, USA
}

\section{A R T I C L E I N F O}

\section{Keywords:}

Chronic kidney disease

High-fat high-sugar diet

Metformin

Liraglutide

Connexins

Pannexin

\begin{abstract}
A B S T R A C T
The comparative effects of the two commonly used antidiabetic drugs metformin and liraglutide on renal pathology and expression of connexin 45 (Cx45) and pannexin 1 (Panx1) in adult obese rats fed high-fat high-sugar diet (HFHSD) were studied. Considering recent data on the profound influence of sex on metformin and liraglutide effects, we compared the effects of both drugs between male and female animals. 44-week-old SpragueDawley rats were separated into 4 groups that were fed: standard diet, HFHSD, HFHSD treated with metformin (s.c., $50 \mathrm{mg} / \mathrm{kg} /$ day) and HFHSD treated with liraglutide (s.c., $0.3 \mathrm{mg} / \mathrm{kg} /$ day). Treatment with metformin or liraglutide lasted for 14 weeks. Histology and immunohistochemistry were performed to quantify renal pathological changes and Cx45 and Panx1 expression. HFHSD caused thickening of the Bowman's capsule (BC). Both metformin and liraglutide failed to ameliorate the BC thickening; metformin even worsened it. Effects on the tubulointerstitial fibrosis score, $\mathrm{BC}$ thickness and $\mathrm{Cx} 45$ and Panx1 expression were sex-dependent. We found a $50 \%$ increase in mitochondria in proximal tubules of metformin- and liraglutide-treated HFHSD-fed rats, but these effects were not dependent on the sex. This is a first study showing that the effects of metformin and liraglutide on kidney pathology in rats fed HFHSD are mostly sex-dependent and that these effects are not necessarily beneficial. Both drugs changed the $\mathrm{Cx} 45$ and Panx 1 expression; hence their effects could be related to amelioration of disruptions in intercellular communication.
\end{abstract}

\section{Introduction}

Metabolic syndrome (MS) consists of different abnormalities including insulin resistance, dyslipidaemia, hypertension and obesity, which have a great impact on the development of cardiovascular disease (Eckel et al., 2005; Prasad, 2014; Zhang and Lerman, 2017). Although these single components of MS are associated with chronic kidney disease (CKD), the prevalence and progression of CKD is also affected directly and independently by MS (Prasad, 2014; Nashar and Egan,
2014). All mechanisms involved in the pathophysiology of MS such as oxidative stress, inflammation, insulin resistance, endothelial dysfunction and increased expression of pro-fibrotic factors play an important role in the pathogenesis of renal damage in CKD (Singh and Kari, 2013; Prasad, 2014). In histopathological examination of damaged kidneys from patients with MS, tubular atrophy, interstitial fibrosis, global and segmental glomerulosclerosis can be observed (Alexander et al., 2009). Kidney damage related to MS resembles the early stage of diabetic nephropathy (DN) characterized by the thickening of the glomerular

\footnotetext{
* Correspondence to: Laboratory for Neurocardiology, Department of Anatomy, Histology and Embryology, University of Split School of Medicine, Šoltanska 2, 21000 Split, Croatia.

E-mail address: natalija.filipovic@mefst.hr (N. Filipović).
} 
basement membrane (GBM) (Tervaert et al., 2010; Zhang and Lerman, 2016), and probably includes Bowman's capsule (BC) thickening as well (Holderied et al., 2015).

Regardless of the CKD initiator, pathological process ultimately leads to the disruption of gap junction intercellular communication, affecting the expression levels of connexin (Cx) proteins that form the communication channels (Toubas et al., 2011). Six identical or different Cx isoforms compose a structure called connexon, each localised on the cell membrane, which is interconnected to the connexon of the neighbouring cell allowing the passage of ions, nutrients and small signalling molecules (Haefliger et al., 2001; Toubas et al., 2011). There are more than $20 \mathrm{Cx}$ family members known today and 9 of them have been detected in different parts of kidney, at least at the mRNA level. In rodents, location, expression and function of renal Cx37, Cx40, Cx43 and Cx45 have been studied the most (Hanner et al., 2010; Haefliger et al., 2001). So far, the expression of $\mathrm{Cx} 45$ has been found in renal vascular smooth muscle cells of afferent and efferent arterioles, intraglomerular and extraglomerular mesangial cells, renin producing juxtaglomerular cells, podocytes and distal tubules (Hanner et al., 2008, 2010). Nevertheless, in our previous work (Saric et al., 2017; Luetic et al., 2020), we found that Cx45 is the most prominent $\mathrm{Cx}$ expressed in proximal tubules of the rat kidney and its expression is substantially decreased in streptozotocin-induced diabetes mellitus (DM) type 1. However, there are still insufficient data about the exact role of $\mathrm{Cx} 45$ and the findings of its distribution in the kidneys are conflicting (Hanner et al., 2010).

In contrast to connexins, members of the pannexin family (Panx1, Panx2 and Panx3) (Willebrords et al., 2017) of Cx-resembling proteins do not form gap junctions, although they assemble hexameric membrane channels (Adamson et al., 2015; Willebrords et al., 2017). Panx1 is widely expressed in different tissues and cells including endothelium of renal vasculature and renal tubules (Abed et al., 2015; Chiu et al., 2018). Although the role of Panx1 in the kidneys is still unknown, some data suggest a role of Panx1 in controlling blood pressure. Panx1 is related to DM and insulin resistance also (Adamson et al., 2015; Cui et al., 2016; Chiu et al., 2018; Luetić et al., 2020).

Insulin resistance is considered to be the most important factor in MS for development of CKD (Prasad, 2014). Therefore, metformin, which improves insulin sensitivity, is potentially a very good option for reducing renal damage related to MS (Nashar and Egan, 2014; Felice et al., 2017). It was demonstrated that administration of metformin in mice with MS reduces mesangial matrix expansion and microalbuminuria (Kim et al., 2013). Renoprotective effects of metformin were observed in various animal and in vitro models of kidney disease, comprising a reduction in GBM thickness and the attenuation of tubulointerstitial fibrosis (Zhang et al., 2017a, 2017b; de Broe et al., 2018). Nevertheless, the use of metformin in patients with CKD is limited by the value of the estimated glomerular filtration rate (eGFR) to prevent the risk of lactic acidosis development (Lazarus et al., 2018). Liraglutide, a glucagon-like peptide-1 (GLP-1) receptor agonist is suggested as a novel therapeutic agent for the treatment of MS considering its potential to reduce insulin resistance (Lim and Eckel, 2014). Protective renal effects of liraglutide in MS including reduced glomerulosclerosis and interstitial fibrosis are observed in obese rats fed a high-fat diet (HFD) (Wang et al., 2018). Likewise, attenuation of renal fibrosis is demonstrated after liraglutide treatment in a rat DM2 model (Chen et al., 2018) and mice with unilateral ureteral obstruction (UUO) (Li et al., 2018).

Observations about the influence of metformin and liraglutide on $\mathrm{Cx}$ expression and function come from studies of the cardiovascular system where both of the drugs upregulated $\mathrm{Cx} 43$ expression and thus improved cardiac function (Noyan-Ashraf Mohammad et al., 2013; Wang et al., 2017). However, there are no data on the effects of MS and the treatment with metformin or liraglutide on expression of Cx proteins in the kidney.

Our study aimed to investigate the comparative effects of metformin and liraglutide treatment on renal pathology and expression of $\mathrm{Cx} 45$ and Panx1 in kidney of rats fed a high-fat high-sugar diet (HFHSD). Based on the previous data about beneficial effects of metformin and liraglutide on renal function, we hypothesized that both therapeutic options can attenuate the progression of CKD and lessen kidney damage. Considering recent data that show the effects of metformin and liraglutide in the other organs are profoundly influenced by sex, we also aimed to compare the effects of both drugs on male and female animals.

\section{Materials and methods}

\subsection{Animals}

A total of 48, 44-week-old Sprague-Dawley rats of both sexes were used in this study. All procedures were approved by the Hungarian Ethical Committee for Animal Research (registration number IV/3796/ 2015). Rats were maintained under controlled laboratory conditions at the Animal Facility, University of Szeged in Szeged, Hungary.

\subsection{Experimental procedure}

Animals were randomly separated into four groups: control rats ( $C$; $n$ $=5$ for female and $\mathrm{n}=6$ for male group), untreated rats fed high-fat high-sugar diet (HFHSD; C 1011 Carbohydrate \& fat-rich diet, Altromin Spezialfutter GmbH \& Co. Lage, Germany; see Supplementary Table $1 ; \mathrm{n}=5$ female and $\mathrm{N}=5$ male animals), metformin-treated rats fed HFHSD (HFHSD+Metf.; $\mathrm{n}=6$ female, $\mathrm{n}=8$ male rats) and liraglutide-treated rats fed HFHSD (HFHSD+Lir.; $\mathrm{n}=5$ female, $\mathrm{n}=8$ male rats). The control group was fed standard chow. Control diet (Altromin 1324) contained 65\% carbohydrate (5\% disaccharide, 39\% polysaccharide), $11 \%$ fat and $24 \%$ protein. HFHS diet (Altromin C1011) contained $56 \%$ carbohydrate (18\% disaccharide, $36 \%$ polysaccharide), $28 \%$ fat and $16 \%$ protein. Six weeks after the beginning of HFHSD, animals from the HFHSD+Metf. group received $50 \mathrm{mg} / \mathrm{kg} /$ day of metformin while the HFHSD+Lir. animals were given $0.3 \mathrm{mg} / \mathrm{kg} /$ day of liraglutide. Both drugs were administered subcutaneously for 14 weeks. There are several daily metformin doses for rats in the literature (from $10 \mathrm{mg} / \mathrm{kg}$ to $500 \mathrm{mg} / \mathrm{kg}$ or even more). We carried out a chronic metformin treatment, therefore we applied the dosage of Narasimhan et al. (2015) in which the rats were treated 30 days with $50 \mathrm{mg} / \mathrm{kg}$ metformin daily and its antidiabetic action was investigated in vivo. The liraglutide dose for rat is very similar in the literature $(0.1-0.4 \mathrm{mg} / \mathrm{kg}$ daily), the only difference is the once or twice administration in $24 \mathrm{~h}$. We have chosen a single daily $0.3 \mathrm{mg} / \mathrm{kg}$ daily dose based on the research of Geddawy et al. (2017) in which metabolic syndrome rats were treated the same way for 6 weeks. Intraperitoneal glucose tolerance test (IPGTT) was made at week 18 . Each rat was treated intraperitoneally with glucose solution (25\%) injecting $2 \mathrm{mg} / \mathrm{kg}$ dose. Blood glucose levels were determined prior and $2 \mathrm{~h}$ after the injection. Blood samples were obtained from tail vein using glucometer (OneTouch UltraMini, Milpitas, USA). After the animals were sacrificed, at Week 19 in deep isoflurane (Forane; Baxter Healthcare Corp. Deerfield, USA) anesthesia by cardiac puncture and collection of whole blood content the prepared serum samples were stored at $-20{ }^{\circ} \mathrm{C}$ for further measurements. The kidneys were removed, quickly cleaned from fat and immediately measured by an analytical scale (ENTRIS64-1S, Sartorius AG, Goettingen, Germany). After the weight measurements, the kidneys were fixed in buffered $4 \%$ paraformaldehyde for further analyses.

\subsection{Blood biochemistry}

Triacylglycerols (TAG) were determined from serum samples obtained in the fasting state, by standard clinical laboratory methods in the Central Clinical Laboratory of Semmelweis University.

\subsection{Histology and immunohistochemistry}

Tissues were washed in phosphate buffer (PBS, pH 7.2), dehydrated and embedded in paraffin wax (Vitlov Uljevic et al., 2018, 2019). Five 
Table 1

Primary and secondary antibodies.

\begin{tabular}{|c|c|c|c|c|c|}
\hline & Antibody & Code No. & Host & Dilution & Source \\
\hline \multirow[t]{2}{*}{ Primary } & Anti-Connexin 45/GJA7/Cx45 antibody & sc-135474 & Rabbit & $1: 100$ & Abcam plc. 330 Cambridge, CB4 OFL, UK \\
\hline & Anti-Pannexin-1/PANX1 Antibody & ABN242 & Rabbit & $1: 100$ & Merck KGaA, Darmstadt, Germany \\
\hline Secondary & $\begin{array}{l}\text { AlexaFluor }(488 \text { Affini Pure Donkey Anti-Rabbit IgG }(\mathrm{H}+\mathrm{L}) \\
\text { Rhodamine Red }{ }^{\mathrm{TM}}-\mathrm{X}(\mathrm{RRX}) \text { AffiniPure Donkey Anti-Rabbit IgG } \\
(\mathrm{H}+\mathrm{L})\end{array}$ & $\begin{array}{l}711-545-152 \\
711-295-152\end{array}$ & Donkey & $1: 400$ & $\begin{array}{l}\text { Jackson Immuno Research Laboratories, Inc., Baltimore, } \\
\text { PA, USA }\end{array}$ \\
\hline
\end{tabular}

$\mu \mathrm{m}$ thick sections were made. After deparaffinization and rehydration, sections were heated at $95^{\circ} \mathrm{C}$ for $12 \mathrm{~min}$ in citrate buffer ( $\mathrm{pH} \mathrm{6.0)}$ and washed with PBS. Incubation with primary antibodies (Table 1) was performed overnight following standard immunohistochemical procedures (Vitlov Uljevic et al., 2018; Luetić et al., 2020). Appropriate secondary antibodies (Table 1 ) were applied for $1 \mathrm{~h}$. The slides were then air-dried and coverslipped (Immu-Mount, Shandon, Pittsburgh, PA, USA).

Alternatively, after deparaffinization, kidney sections were stained by phosphotungstic acid hematoxylin (PTAH), periodic acid Schiff (PAS), or Mallory's trichrome staining.

\subsection{Data acquisition and analyses}

Sections were viewed and analysed by a blinded pathologist using a microscope (BX61, Olympus, Tokyo, Japan) equipped with a cooled digital camera (DP71, Olympus, Tokyo, Japan). For further analyses, ImageJ software (National Institutes of Health, Bethesda, MD, USA) was used.

In each section expression of $\mathrm{Cx} 45$ was determined in 7-8 visual fields of kidney cortex captured at $400 \times$ magnification and constant exposure time. A red granular pattern was interpreted as immunoreactive for $\mathrm{Cx} 45$ positivity. The percentage of immunoreactive area in the total examined area was calculated.

Expression of Panx1 was analysed in glomeruli and tubules using 10 randomly selected cortical areas of the kidney per animal (photographed at $400 \times$ magnification). Green granular deposits were interpreted as positive for Panx1. Quantification was made by counting deposits in glomeruli and tubules separately.

For PAS analyses, 20 non-overlapping areas of kidney cortex with at least one glomeruli included per section were photographed at a magnification of $400 \times$.

BC thickness was also analysed in 20 glomeruli. Thickness of the BC was measured from at least six different points which were randomly selected using a grid tool with random offset in ImageJ; the exact points of measurement were intersections of vertical and horizontal lines with the outer membrane of BC.

From the obtained images of kidney cortex, 20 glomeruli were randomly examined in which glomerular damage was estimated and graded as 0 - normal, 1 - minimal sclerosis $(<25 \%), 2-$ mild sclerosis
(25-50\%), 3 - moderate sclerosis (50-75\%), 4 - severe sclerosis ( $>75 \%)$. The glomerular score for each animal was determined using the formula: $\left(0 \times \mathrm{x}_{0}\right)+\left(1 \times \mathrm{n}_{1}\right)+\left(2 \times \mathrm{n}_{2}\right)+\left(3 \times \mathrm{n}_{3}\right)+\left(4 \times \mathrm{n}_{4}\right) / \mathrm{n}_{0}+\mathrm{n}_{1}+$ $\mathrm{n}_{2}+\mathrm{n}_{3}+\mathrm{n}_{4}$. Element $\mathrm{n}_{\mathrm{x}}$ represents the number of equally graded glomeruli (Maric et al., 2004; Yabuki et al., 2006).

The estimation of tubulointerstitial fibrosis was made using the photomicrographs of the entire cortical area of each kidney section stained by Mallory's trichrome staining which were obtained under 100 $\times$ magnification. Tubulointerstitial fibrosis was graded as 0 - normal, 1 less than 10\%, $2-10-25 \%, 3-25-75 \%$, 4 - more than $75 \%$ fibrosis (Yabuki et al., 2006; Glastras et al., 2016).

For analysis of mitochondria, 17-21 visual fields of PTAH-stained sections captured at $400 \times$ magnification were analysed, to quantify the mitochondria covered $\%$ area of the section.

\subsection{Statistical analyses}

For calculation of the sample size we used the Mead's resource equation (Mead et al., 2012; Arifin, 2017), for the case of one-way group (between-subject) comparison. Accordingly, the calculated minimal size of the experimental group should be $n=4$. PAST 3.22 Software was used for statistical analyses (Hammer et al., 2001). In order to compare data between experimental groups Kruskal-Wallis test, followed by the Mann-Whitney test was used. Statistical significance was set at $\mathrm{p}<0.05$.

\section{Results}

\subsection{Kidney weights and biochemical parameters}

Kidney weights and biochemical parameters are presented in a Table 2. We observed slightly higher total kidney weights in female HFHSD+Lir. (absolutely and relatively to the body mass), but these difference $s$ were not significant ( $p=0.0345$ in comparison to $C$, but Kruskal-Wallis test was $p=0.0874)$. In opposite, we noticed significantly lower total kidney weight in male HFHSD+Lir. rats $(\mathrm{p}=0.0239$ compared to Ctrl. and $\mathrm{p}=0.0181$ in comparison to HFHSD). However, there was no significant difference in renal mass of male rats, when expressed as \% of body weight. We observed disturbed blood glucose control in all female animals (including the Ctrl. group), that were not able to restore glycaemia two hours after receiving intraperitoneally 2

Table 2

Kidney weights and biochemical parameters.

\begin{tabular}{|c|c|c|c|c|c|c|}
\hline & & \multicolumn{5}{|c|}{ Parameter Mean \pm SD (unit) } \\
\hline & & $\begin{array}{l}\text { Total kidney weight } \\
\text { (g) }\end{array}$ & $\begin{array}{l}\text { Total kidney weight (\% of body } \\
\text { weight) }\end{array}$ & $\begin{array}{l}2 \mathrm{hr} \text { blood glucose (mg/ } \\
\mathrm{dL})\end{array}$ & $\begin{array}{l}2 \mathrm{hr} \text { blood glucose (\% of } \\
\text { baseline) }\end{array}$ & $\begin{array}{l}\text { Triacylglycerols } \\
(\mathrm{mM})\end{array}$ \\
\hline \multirow[t]{4}{*}{ Female } & Ctrl. & $2,04 \pm 0,20$ & $0,55 \pm 0,03$ & $242,75 \pm 128,24$ & $342,33 \pm 147,35$ & $0,90 \pm 0,25$ \\
\hline & HFHSD & $2,33 \pm 0,65$ & $0,52 \pm 0,08$ & $419,80 \pm 134,93$ & $622,03 \pm 232,68$ & $1,48 \pm 0,75$ \\
\hline & HFHSD+Metf. & $2,33 \pm 0,28$ & $0,56 \pm 0,05$ & $291,67 \pm 103,84$ & $408,79 \pm 153,02$ & $1,21 \pm 0,48$ \\
\hline & HFHSD+Lir. & $2,42 \pm 0,19$ & $0,69 \pm 0,10$ & $366,20 \pm 133,64$ & $479,50 \pm 226,60$ & $0,68 \pm 0,33^{\#} \$$ \\
\hline Female - $p$ & & 0,1434 & 0,0874 & 0,2809 & 0,1364 & 0,0454 \\
\hline \multirow[t]{4}{*}{ Male } & Ctrl. & $3,96 \pm 0,39$ & $0,66 \pm 0,07$ & $98,00 \pm 3,56$ & $146,37 \pm 5,30$ & $0,52 \pm 0,08$ \\
\hline & HFHSD & $3,62 \pm 0,22$ & $0,55 \pm 0,07$ & $195,00 \pm 97,86 *$ & $247,43 \pm 106,23 *$ & $0,91 \pm 0,24 *$ \\
\hline & HFHSD+Metf. & $3,82 \pm 0,37$ & $0,58 \pm 0,07$ & $192,83 \pm 59,90 *$ & $289,90 \pm 88,57 *$ & $1,00 \pm 0,34 *$ \\
\hline & HFHSD+Lir. & $3,49 \pm 0,57 * \$$ & $0,58 \pm 0,07$ & $223,25 \pm 107,66 *$ & $276,58 \pm 106,94 *$ & $0,73 \pm 0,26$ \\
\hline Male $-p$ & & 0,0335 & 0,1336 & 0,0209 & 0,0171 & 0,0059 \\
\hline
\end{tabular}

Kruskal-Wallis test followed by Man-Whitney test. $\mathrm{p} \leq 0.05$ compared to: * Ctrl.; \# HFHSD; \$ HFHSD+Metf. 


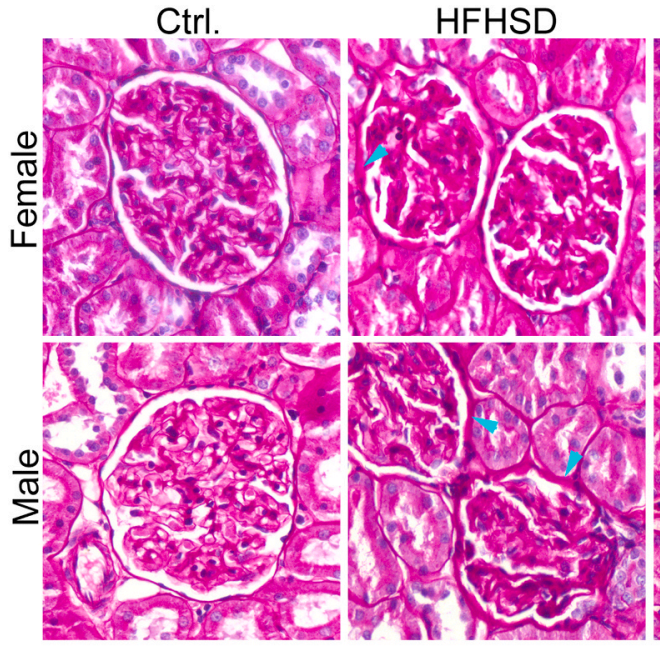

BC-F

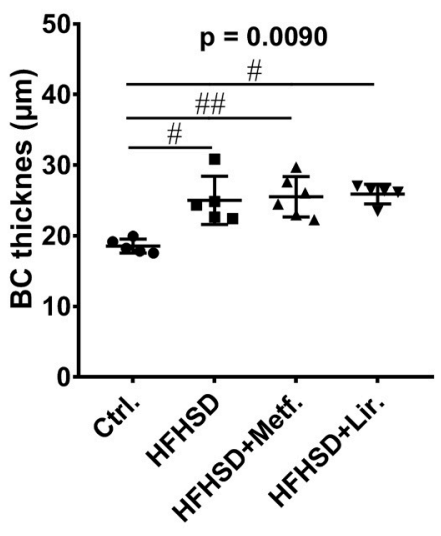

Glom.score-F

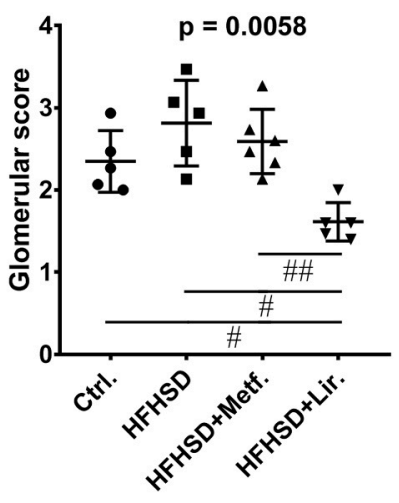

HFHSD+Metf.
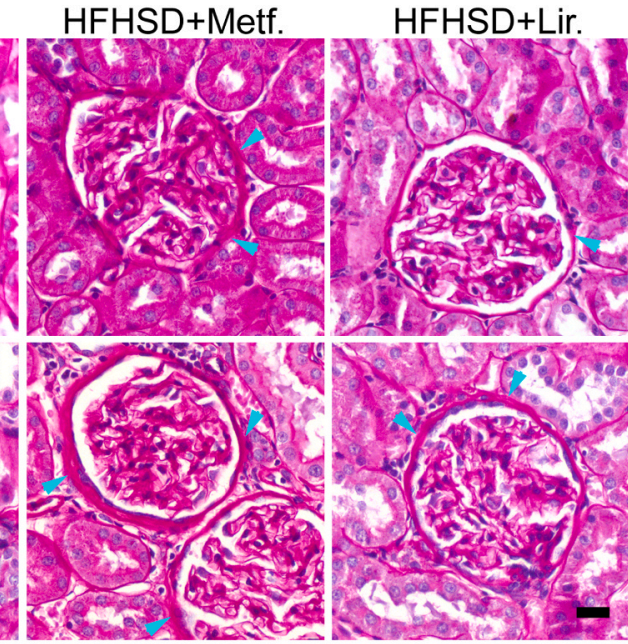

BC-M

Fig. 1. Periodic acid Schiff (PAS) staining of kidney sections. Representative photomicrographs of renal sections stained with PAS. Objective magnification: $40 \times$. BC, Bowman's capsule; arrowheads indicate thickening of the BC; Ctrl., control group; HFHSD, untreated high-fat high-sugar diet fed group; HFHSD+Metf., metformin-treated HFHSD fed group; HFHSD+Lir., liraglutide-treated HFHSD fed group; F, female; $M$, male. \# - p $<0.05$, \#\# - $\mathrm{p}<0.01$ significant difference between indicated female groups; * $-\mathrm{p}<0.05, * *-\mathrm{p}<0.01$, $* * *-\mathrm{p}<0.001$ significant difference between indicated male groups (Kruskal-Wallis ANOVA, followed by the Mann-Whitney test). Graphs show Mean \pm SD. Scale-bar $=20 \mu \mathrm{m}$.

$\mathrm{mg} / \mathrm{kg}$ glucose. However, rats in Ctrl. female group had $342.33 \pm$ $147.35 \%$ of initial glucose values $2 \mathrm{hr}$ after the glucose injection, while rats in untreated HFHSD female group had $622.03 \pm 232.68 \%$ of initial glucose value and these values were slightly lower in HFHSD+Metf. and HFHSD+Lir. groups, but these differences were not significantly different. In opposite to female, male rats in Ctrl. group were able to effectively restore glycaemia (146.37 $\pm 5.30 \%$ of initial blood glucose value $2 \mathrm{hr}$ after intraperitoneal glucose injection). However, HFHSD in male rats resulted in increased $2 \mathrm{hr}$-blood glucose value $(\mathrm{p}=0.0518$ compared to the Ctrl.), which was not restored by metformin or liraglutide treatment (Ctrl. vs. HFHSD+Metf. $\mathrm{p}=0.0142$; Ctrl. vs. HFHSD + Lir. $p=0.0085$ ). In addition, we observed an increase in serum triacylglycerols in female HFHSD and HFHSD+Metf. Groups, but these differences did not reach significant value. However, in HFHSD+Lir. group we found significantly lower values of serum triacylglycerols, when compared to HFHSD ( $\mathrm{p}=0.0481)$ of HFHSD+Metf. group ( $\mathrm{p}=$ 0.0348). In agreement with that, in male HFHSD and HFHSD+Metf. groups, serum triacylglycerol values were significantly higher in comparison to Ctrl. group ( $\mathrm{p}=0.0439$ and $\mathrm{p}=0.0053$; respectively); while serum triacylglycerols were not increased in rats from HFHSD+Lir. group. 


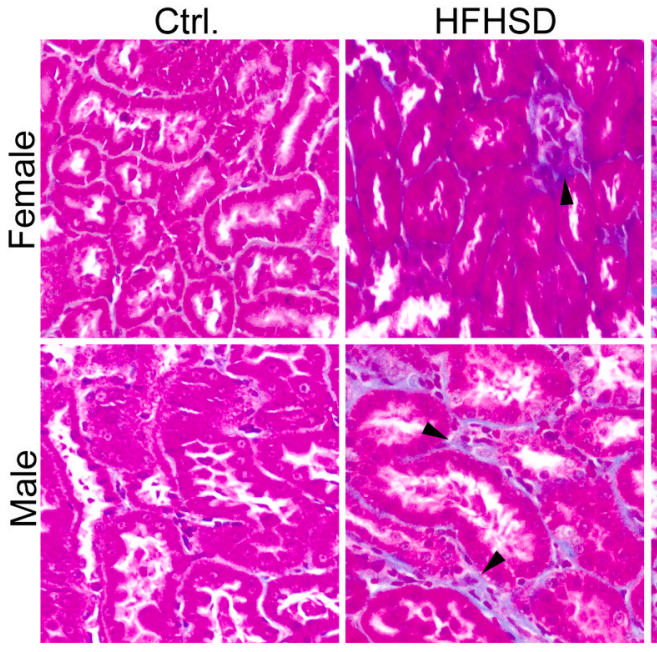

T/l fibrosis-F

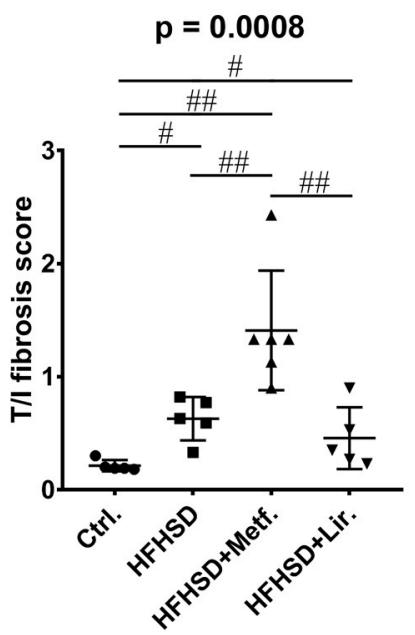

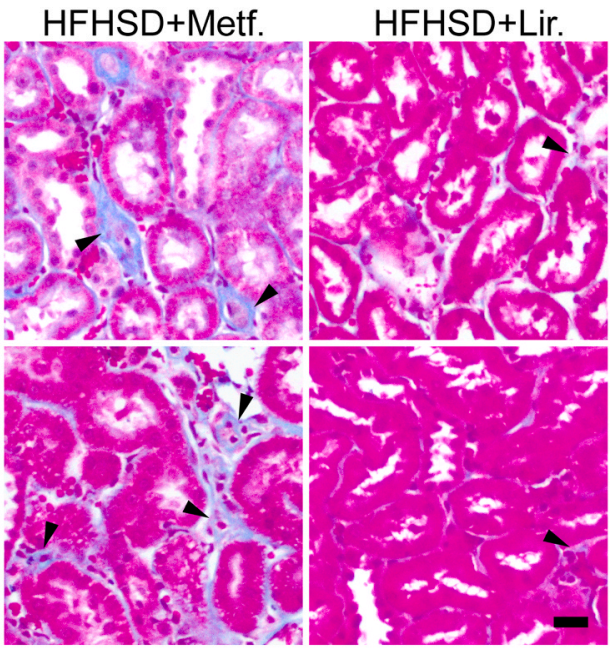

Fig. 2. Drug associated alteration of tubulointerstitial fibrosis. Representative photomicrographs of renal sections stained by Mallory's trichrome staining. Objective magnification: $40 \times . \mathrm{T} / \mathrm{I}$, tubulointerstitial; arrowheads indicate T/I fibrosis; Ctrl., control group; HFHSD, untreated high-fat high-sugar diet fed group; HFHSD+Metf., metformin-treated HFHSD fed group; HFHSD+Lir., liraglutide-treated HFHSD fed group; F, female; $M$, male. \# - p $<0.05$, \#\# - $\mathrm{p}<0.01$ - significant difference between indicated female groups; $* *-\mathrm{p}<0.01, * * *$ $\mathrm{p}<0.001$ significant difference between indicated male groups (Kruskal-Wallis ANOVA, followed by the Mann-Whitney test). Graphs show Mean \pm SD. Scale-bar $=20 \mu \mathrm{m}$.
3.2. The influence of metformin and liraglutide therapy on Bowman's capsule thickness

HFHSD significantly increased the thickness of the BC in female (Ctrl. vs. HFHSD $\mathrm{p}=0.0122$; Ctrl. vs. HFHSD+Metf. $\mathrm{p}=0.0081$; Ctrl. vs. HFHSD + Lir. $\mathrm{p}=0.0122$ ) and male rats (Ctrl. vs. HFHSD $\mathrm{p}=0.0081$; Ctrl. vs. HFHSD + Metf. $\mathrm{p}=0.0024$; Ctrl. vs. HFHSD + Lir. $\mathrm{p}=0.0024$; Fig. 1). In females, both metformin and liraglutide failed to demonstrate any significant effect on the thickness of BC in HFHSD fed rats. In males, however, HFHSD fed rats treated with metformin had the thickest BC, and the thickness was significantly greater when compared to the $\mathrm{BC}$ of the animals from all-male HFHSD groups ( $\mathrm{p}=0.0104 \mathrm{vs}$. HFHSD and $\mathrm{p}$ $=0.0009$ vs. HFHSD + Lir.).

\subsection{Metabolic syndrome-related glomerulosclerosis}

We did not observe significant differences between groups in the PAS glomerular score, except a significant decrease in liraglutide-treated females in comparison to all other female groups ( $p=0.0157$ vs. Ctrl.; $\mathrm{p}=0.0119$ vs. HFHSD and $\mathrm{p}=0.0080$ vs. HFHSD+Metf.; Figure1).

\subsection{Drug-associated alteration of tubulointerstitial fibrosis}

HFHSD resulted in tubulointerstitial fibrosis in rats of both, male (Ctrl. vs. HFHSD $\mathrm{p}=0.0081$ ) and female rats (Ctrl. vs. HFHSD
T/l fibrosis-M

$p=0.0001$

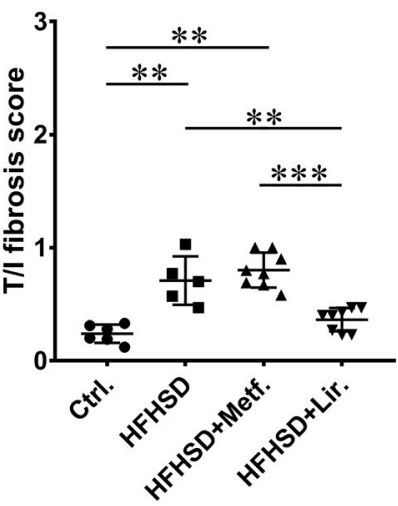

$\mathrm{p}=0.0119$; Fig. 2). Administration of metformin markedly increased the degree of fibrosis (Ctrl. vs. HFHSD+Metf. in male $\mathrm{p}=0.0024$ and in female $\mathrm{p}=0.0074$ ) and in female rats it even aggravated fibrotic changes compared to the female HFHSD group $(\mathrm{p}=0.0075)$. Nevertheless, liraglutide significantly reduced tubulointerstitial fibrosis in HFHSD fed male rats $(\mathrm{p}=0.0063$ vs. HFHSD and $\mathrm{p}=0.0009$ vs. HFHSD+Metf.).

\subsection{PTAH staining - drug-associated alteration of mitochondria}

HFHSD did not cause significant changes in the mitochondria \% area (Fig. 3). On the other hand, administration of either metformin to the HFHSD fed animals significantly increased the mitochondria $\%$ area in both, female ( $p=0.0081$ vs. Ctrl. and $\mathrm{p}=0.0081$ vs. HFHSD) and male rats ( $\mathrm{p}=0.0104$ vs. HFHSD). The same effect was also found for the liraglutide: in female ( $\mathrm{p}=0.0122$ vs. Ctrl. and $\mathrm{p}=0.0122$ vs. HFHSD), as well as in male animals ( $\mathrm{p}=0.0168$ vs. Ctrl. and $\mathrm{p}=0.0043$ vs. HFHSD). These effects obviously were not dependent on the sex of the animals.

\subsection{Expression of Cx45 and Panx1 in the rat kidneys}

We observed the dominant $\mathrm{Cx} 45$ expression in proximal tubules with a relatively low level of expression in glomeruli (Fig. 4). This was in agreement with results of our previous study (Luetic et al., 2020), in 

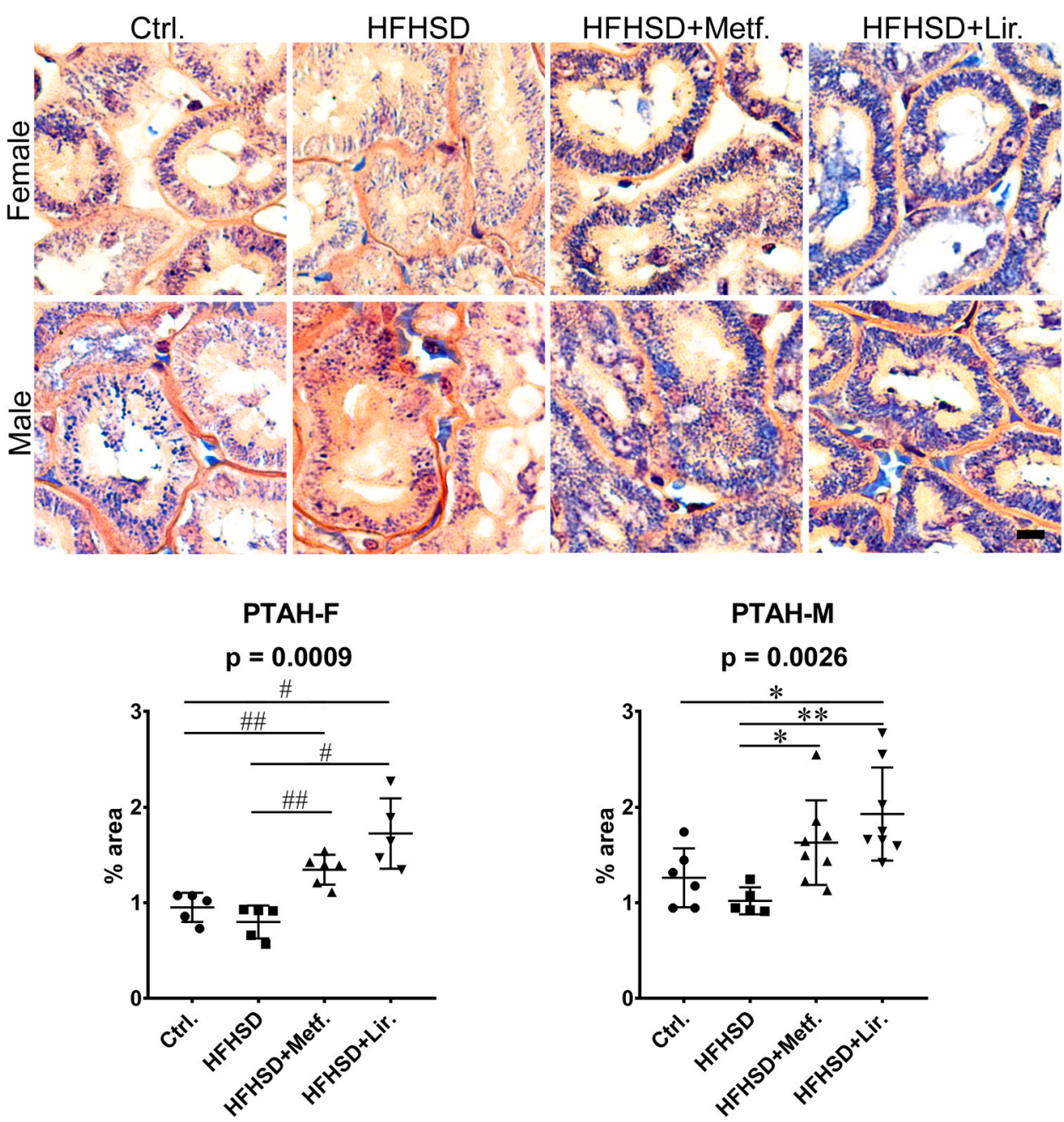

which proved the prevailing presence of the Cx45 in the proximal tubules, on a base of PTC morphology and the co-localization with the DBA, a Dolichos biflorus agglutinin. In female animals, liraglutide upregulated Cx45 expression in comparison with the control and HFHSD groups $(\mathrm{p}=0.0122$ and $\mathrm{p}=0.0216$, respectively). In male rats, expression of $\mathrm{Cx} 45$ in the HFHSD+Metf. group was markedly increased compared to the control group ( $\mathrm{p}=0.0239$ ). However, there was no difference in Cx45 expression between rats from the HFHSD and control groups. Expression of $\mathrm{Cx} 45$ was significantly higher in HFHSD+Lir. male group, when compared to control $(p=0.0168)$ and HFHSD group $(\mathrm{p}=0.0103)$.

The pannexin dots appeared mostly in glomeruli. In case that they were found outside the glomeruli, their appearance was located in the tubuli, mostly in DCT. This finding was in agreement with our previous study on diabetic rats (Luetić et al., 2020). Panx1 immunoreactive puncta were only rarely found in the interstitium or in the endothelium of the vessels. In glomeruli, expression of Panx1 was significantly higher in male rats treated with metformin in comparison to the control group ( $\mathrm{p}=0.0188$; Fig. 5). In females, expression of Panx1 in glomeruli was the highest in HFHSD+Lir. group ( $\mathrm{p}=0.0114$ vs. Ctrl.; $\mathrm{p}=0.0204$ vs. HFHSD and $\mathrm{p}=0.0077$ vs. HFHSD+Metf.). In tubules, Panx1 was upregulated in the female group on metformin therapy ( $\mathrm{p}=0.0080 \mathrm{vs}$. Ctrl. and $\mathrm{p}=0.0081$ vs. HFHSD+Lir.). Tubulo/interstitial expression of Panx1 in male rats was increased in all groups fed HFHSD when compared to control animals (Ctrl. vs. HFHSD $\mathrm{p}=0.0358$; Ctrl. vs. HFHSD+Metf. $\mathrm{p}=0.0081$ and Ctrl. Vs. HFHSD+Lir. $\mathrm{p}=0.0280$ ).
Fig. 3. Phosphotungstic acid hematoxylin (PTAH) - drug associated alteration of mitochondria. Representative photomicrographs of renal sections stained by PTAH. Objective magnification: $40 \times$. Ctrl., control group; HFHSD, high-fat high-sugar diet fed group; HFHSD+Metf., metformin-treated HFHSD fed group; HFHSD+Lir., liraglutide-treated HFHSD fed group; F, female; $M$, male. \# - p $<0.05$, \#\# - $\mathrm{p}<0.01$ - significant difference between indicated female groups; * $-\mathrm{p}<0.05, * *$ $\mathrm{p}<0.01$ significant difference between indicated male groups (Kruskal-Wallis ANOVA, followed by the Mann-Whitney test). Graphs show Mean \pm SD. Scale-bar $=20 \mu \mathrm{m}$.

\section{Discussion}

In this study, we investigated the comparative effects of metformin and liraglutide treatment on renal pathology and expression of $\mathrm{Cx} 45$ and Panx1 in the kidneys of Sprague-Dawley HFHSD-fed rats and compared the effects of both drugs between male and female animals. We found disturbed blood glucose control in all female animals (including the Ctrl. group), that were not able to restore glycaemia two hours after receiving intraperitoneally $2 \mathrm{mg} / \mathrm{kg}$ glucose. In opposite to female, male rats in Ctrl. group were able to effectively restore glycaemia while, HFHSD in resulted in increased $2 \mathrm{hr}$-blood glucose value, which was not restored by metformin or liraglutide treatment. In addition, we found that liraglutide treatment was able to decrease serum triacylglycerol values of HFHSD fed rats, but metformin did not.

Glomerular damage is a feature of MS and includes mesangial matrix expansion, podocyte injury and glomerular fibrosis (Kim et al., 2013). In addition to the glomerular damage, MS also affects other parts of the nephron, causing tubular atrophy and interstitial fibrosis (Alexander et al., 2009). The most prominent pathological change that we found in kidneys of HFHSD-fed rats was pronounced tubulointerstitial fibrosis. In female rats, metformin treatment did not ameliorate tubulointerstitial fibrosis; rather it even worsened it. In contrast, in male animals, treatment with liraglutide significantly ameliorated tubulointerstitial fibrosis. Our findings are concordant with those of other studies that showed beneficial effects of liraglutide in preventing the progression of tubulointerstitial fibrosis in HFD-fed rats (Wang et al., 2018), in a rat DM2 model (Chen et al., 2018) and in a mouse UUO model of renal 

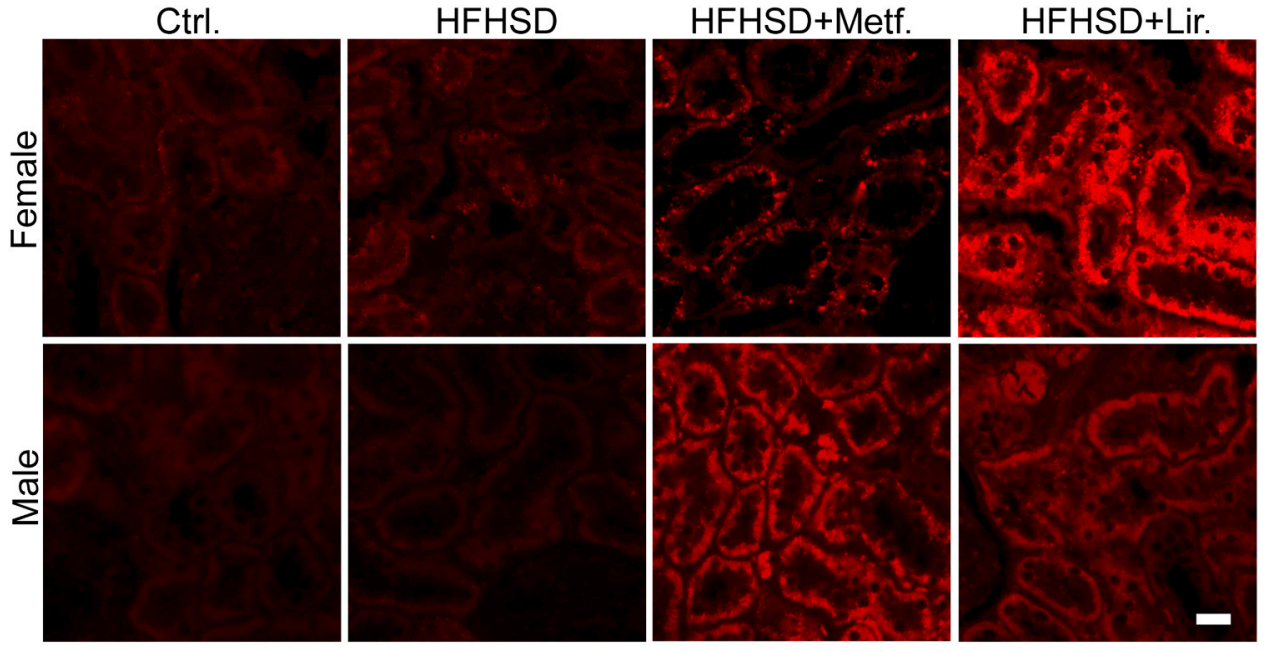

Fig. 4. Expression of connexin $45(\mathrm{Cx} 45)$ in the kidneys of experimental rats. Representative photomicrographs of renal sections stained by Cx45-immunohistochemistry. Objective magnification: $40 \times$. Ctrl., control group; HFHSD, high-fat high-sugar diet fed group; HFHSD+Metf., metformin-treated HFHSD fed group; HFHSD+Lir., liraglutide-treated HFHSD fed group; F, female; $M$, male. \# - p $<0.05$ significant difference between indicated female groups; * - p $<0.05$ - significant difference between indicated male groups (Kruskal-Wallis ANOVA, followed by the Mann-Whitney test). Graphs show Mean \pm SD. Scale-bar $=20 \mu \mathrm{m}$.
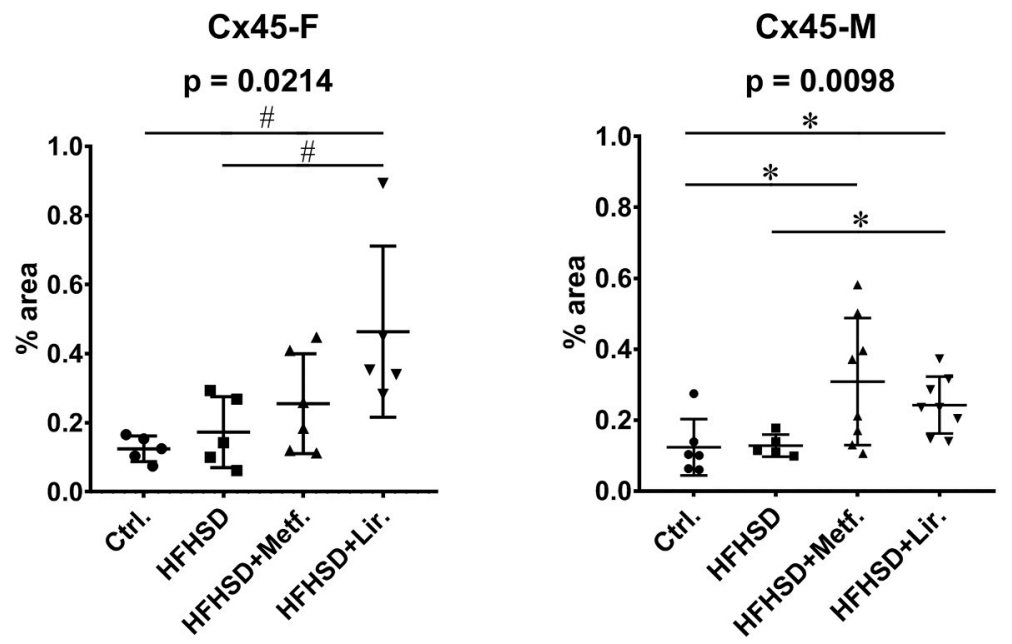

fibrosis (Li et al., 2018). However, female specific whorsening of the tubulointerstitial fibrosis in metformin-treated rats was unexpected.

The most prominent change that we found in glomeruli was the thickening of the $\mathrm{BC}$, which was evident in all groups of animals fed HFHSD. The treatment with each of the medications did not ameliorate it. Moreover, metformin treatment even worsened it, specifically in male rats. We did not find significant changes in the glomerular PAS score between experimental groups, except for a significant decrease in the female group treated with liraglutide, even in comparison with the control group. This could be explained by amelioration of normal ageing changes in glomeruli by liraglutide. Changes in glomeruli were subtle, and the only visible sign of damage was BC thickening. This could be a reason why this type of damage might often go unnoticed and underestimated in pathological examination. In support, we did not observe substantial changes in total renal mass expressed as $\%$ of body weight caused by HFHSD, although we found slightly higher total kidney weights in female HFHSD+Lir. and lower total kidney weight in male HFHSD+Lir. Previous studies of obesity-induced kidney injury in rats have shown that liraglutide therapy has beneficial effects on fibrotic lesions (Wang et al., 2018). Gender-related variations of liraglutide effects could be explained by differences in drug metabolism. Since in males an increased rate of elimination of liraglutide was observed (Cataldi et al., 2019), there is a shortened period for liraglutide to achieve its full therapeutic potential.

Histopathological changes in the kidneys related to MS are similar to the ones seen in DN due to their overlapping pathophysiological processes (Zhang and Lerman, 2017). In the early stage of DN, thickening of the GBM is evident by electron microscopy (Tervaert et al., 2010). It was also proven that metabolic alterations in DN lead to BC thickening as well (Holderied et al., 2015). Although there are still no data in literature about, these changes very likely occur in MS. Our results are the first to show the thickening of the $\mathrm{BC}$ in association with HFHSD. Moreover, gender-related changes in the $\mathrm{BC}$ thickness were observed concerning the therapeutic option where metformin significantly increased the thickness of $\mathrm{BC}$ in male animals when compared to all other groups of males.

Besides, we found an increase of approximately $50 \%$ in mitochondria in proximal tubules of both the metformin- and liraglutide-treated HFHSD fed rats. These results are in agreement with numerous studies that relate both metformin and liraglutide with biogenesis, function and reduction of oxidative stress in mitochondria of different organs (Pintana et al., 2013; Sa-Nguanmoo et al., 2017; Karise et al., 2019; Pal et al., 2019; Vial et al., 2019; Wu et al., 2019). However, we found that these effects were not sex-specific.

Cx45 is far more intriguing than all other Cxs relevant to renal function and pathology, because its role in the kidneys is still unexplained and precise localisation remains unclear (Hanner et al., 2010). In the present study, as we had already observed (Saric et al., 2017; Luetić et al., 2020), the most prominent expression of Cx45 was observed in proximal tubules, suggesting its involvement in various processes which occur in this part of the nephron. Concerning a notable role of the proximal tubules in the development of tubulointerstitial 

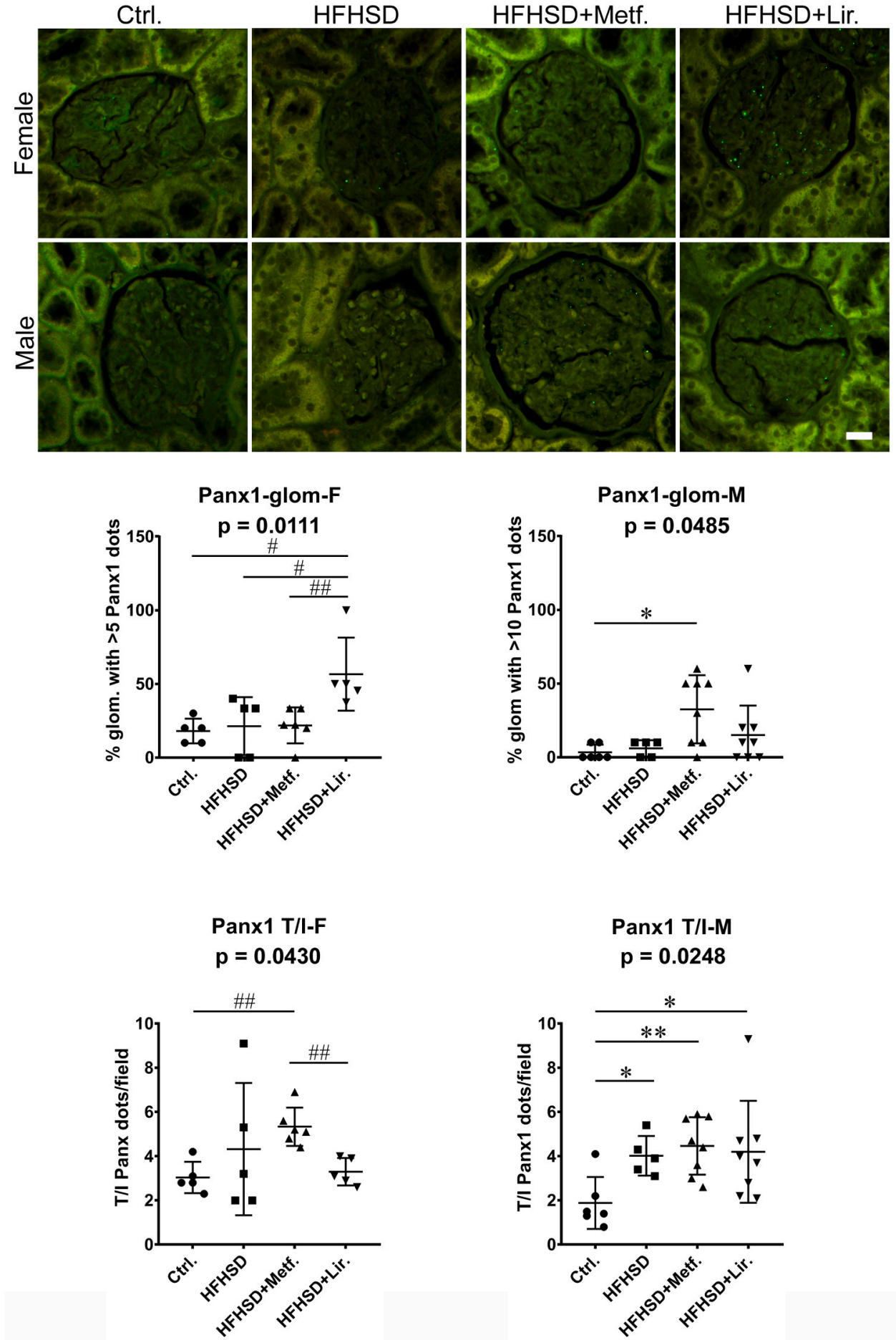

Fig. 5. Expression of pannexin 1 (Pnx1) in the kidneys of experimental rats. Representative photomicrographs of renal sections stained by Pnx1-immunohistochemistry. Objective magnification: $40 \times$. Ctrl., control group; HFHSD, high-fat high-sugar diet fed group; HFHSD+Metf., metformin-treated HFHSD fed group; HFHSD+Lir., liraglutide-treated HFHSD fed group; F, female; M, male. \# - p $<0.05$, \#\# - $\mathrm{p}<0.01$; significant difference between indicated female groups; * - p $<0.05 ; * *-p<0.01$ significant difference between indicated male groups (Kruskal-Wallis ANOVA, followed by the Mann-Whitney test). Graphs show Mean \pm SD. Scale-bar $=20 \mu \mathrm{m}$. fibrosis (Gewin, 2018), the changes of $\mathrm{Cx} 45$ expression may be related to the progression of the fibrotic lesions. Our results have shown that expression of $\mathrm{Cx} 45$ is gender- and drug-dependent; in male rats treated with metformin the level of $\mathrm{Cx} 45$ was the highest whereas in females liraglutide had the same effect. Drug-related changes in Cx expression were observed in previous studies on the cardiovascular system where both metformin and liraglutide increased the levels of Cx43 (Noyan-Ashraf Mohammad et al., 2013; Wang et al., 2017). These findings are in agreement with those from studies in cardiac cells in vitro (Wang et al., 2017) and mice with HFD-induced obesity associated with MS (Noyan-Ashraf Mohammad et al., 2013). Considering our data, upregulation of $\mathrm{Cx} 45$ could be a mechanism associated with amelioration of the tubulointerstitial fibrosis, since we did not find the increase in Cx45 expression in untreated HFHSD-fed animals. The sex difference could be due to the slower tubular elimination of liraglutide in females (Cataldi et al., 2019) which may lead to a prolonged effect of liraglutide in renal tissue.

An increase of $\mathrm{Cx} 45$ tubular expression in liraglutide treated rats fed HFHSD could be at least partially explained by ability of liraglutide to restore disturbed endoplasmic reticulum (ER) homeostasis. Namely, HFD causes ER stress and affects folding and trafficking of proteins, including the connexins, with accumulation of misfolded forms which 
can ultimately lead to apoptosis and cell death (Ozcan et al., 2004; Liu et al., 2020). Furthermore, ER stress can trigger mechanisms of nonapoptotic cell death characterized by autophagy (Kawakami et al., 2009). A number of studies proved restoring effects of liraglutide and of other GLP-1 analogs on the ER stress in different tissues and models (Panagaki et al., 2017; Sharma et al., 2011; Bretón-Romero et al., 2018; Liu et al., 2020; Ren et al., 2020; Fu et al., 2020). By restoring the damaged ER function, liraglutide treatment could increase the rate of protection and proper folding of connexins, with a lower rate of improperly folded connexins predicted for autophagic degradation. Metformin could also have similar role which leads to upregulation of Cx45 as it was found to decrease ER stress and inhibits autophagy pathways in peripheral blood mononuclear cells of patients with type 2 diabetes (Diaz-Morales et al., 2018). In support to the above mentioned, Kawakami et al. demonstrated that ER stress induces autophagy in proximal tubular cells (Kawakami et al., 2009), where we observed Cx45 upregulation when each drug was used, indicating that they might reduce a rate of ER stress and connexin autophagy.

The role of Panx1 in the kidneys is still not completely clear. It is involved in pathophysiology of insulin resistance and regulation of blood pressure (Chiu et al., 2018). In our previous study, we reported significant upregulation of Panx1 in the kidneys of rats with DM1 (Luetić et al., 2020) implicating its possible role in various mechanisms associated with DM such as inflammation, endothelial dysfunction and fibrosis (Singh and Kari, 2013). Pro-inflammatory effects of Panx1 are well known (Poudel and Okusa, 2019) and recently some studies observed its pro-fibrotic effects as well (Cogliati et al., 2016a). In the present study, we demonstrated a significant increase of tubular Panx1 expression in metformin-treated female rats which could be connected to the observed tubulointerstitial fibrosis that was the most prominent in the same group of animals. Although there is still no data which support the involvement of Panx1 in renal fibrosis, a few studies proved the association of Panx1 with the development of fibrosis in the myocardium (Dolmatova et al., 2012; Cogliati et al., 2016a). Panx1 is a possible marker of early renal damage and could be a therapeutic target for attenuation of acute kidney damage (Poudel and Okusa, 2019). Inhibition of Panx1 channels in mice is beneficial in experimental acute kidney injury (Poudel and Okusa, 2019). In glomeruli, however, we demonstrated upregulation of Panx1 in the group of male rats on metformin therapy. As mentioned before, metformin-treated male rats had the thickest $\mathrm{BC}$ so we can speculate that there is a positive correlation between the process of membrane thickening and expression of Panx1 in renal tissue. In support of this idea, is the finding that Panx1 channels activate fibroblasts in cardiac injury which then produce extracellular matrix (ECM) proteins and collagen leading to fibrosis (Dolmatova et al., 2012). This mechanism could also be responsible for activation of glomerular parietal epithelial cells and their production of ECM proteins and collagen secretion, causing thickening of BC.

We demonstrated considerable differences between male and female animals regarding the therapy they received. The sex-specific effect of metformin was observed previously in a study in which metformin reversed and prevented neuropathic pain in only male mice (Inyang et al., 2019). Sex dependent effect of metformin could be explained by female hormones, primarily estrogen. Estrogen is involved in many physiological functions including growth, cell differentiation and regulation of ECM protein production (Soldano et al., 2010; Park et al., 2017). Some of these processes are involved in the BC thickening (Holderied, 2015). Metformin has a significant role in inhibiting mRNA and protein expression of estrogen regulated genes so the production of ECM proteins is blocked (Park et al., 2017). This inhibition is probably more intensified in females due to the higher estrogen levels. This could explain why male animals had the thickest BC. Nevertheless, previous studies found lower urinary excretion of metformin in female in comparison to male rats, which was caused by different expression levels of organic cation transporter 2 (OCT2) in proximal tubules (Ma et al., 2016; Gai et al., 2016). and accumulation of metformin in the kidneys
(Ma et al., 2016). Since the expression of OCT2 is considerably increased in HFD-induced obese mice (Gai et al., 2016), so HFHSD has additional effects on gender-related kidney injury in metformin-treated male rats with MS. The main shortage of this study is that, as many of the similar studies, we used only immunohistochemistry for analysis of connexin and pannexin expression (Kanczuga-Koda et al., 2004, 2006; Camelliti et al., 2004; Torres et al., 2005; Takenaka et al., 2008; Paštar et al., 2021; Lozić et al., 2021; Jurić et al., 2020; Kosović et al., 2020a, 2020b; Luetić et al., 2020). However, results of the western blot analysis would give us an information only about the amount of certain protein in tissue, but not on the distribution of the certain protein in cells or in tissue (Cogliati et al., 2016b).

In conclusion, we demonstrated for the first time that HFHSD causes thickening of the $\mathrm{BC}$ in glomeruli. Both of the treatments failed to ameliorate the observed BC thickening caused by the HFHSD treatment. Moreover, using metformin even worsened it. We found that the effects of metformin and liraglutide in kidneys of HFHSD-fed rats are mostly sex-dependent. Besides the differences in the tubulointerstitial fibrosis score and the thickness of the BC, sex-dependent effects also included changes in renal $\mathrm{Cx} 45$ and Panx 1 expression that had not been previously studied. Both drugs changed the Cx45 and Panx 1 expression, pointing out that their effects on the kidney could be related to amelioration of disruptions in gap junction-mediated intercellular communication. On the other hand, we found a tremendous increase in cellular mitochondria in the proximal tubuli of both metformin- and liraglutide-treated HFHSD-fed rats, but these effects were not dependent on the sex of the animals.

\section{Funding}

This work was supported by Cedars-Sinai Medical Center's International Research and Innovation in Medicine Program, and the Association for Regional Cooperation in the Fields of Health, Science and Technology (RECOOP HST Association); the Ministry of Science, Education and Sports, Republic of Croatia and Croatian Scientific Foundation (HRZZ; grants no. DOK-2015-10-7725 and HRZZ-IP-2014-092324); Ministry of Human Capacities. [Hungary grant 20391-3/2018/ FEKUSTRAT].

\section{Conflict of interest statement}

On behalf of all authors, corresponding author declares no conflict of interest.

\section{Acknowledgements}

This study was supported by Cedars-Sinai Medical Center's International Research and Innovation in Medicine Program, the Association for Regional Cooperation in the Fields of Health, Science and Technology (RECOOP HST Association), the participating Cedars-Sinai Medical Center - RECOOP Research Centers (CRRCs); the Ministry of Science, Education and Sports, Republic of Croatia; Croatian Scientific Foundation (HRZZ; grants no. DOK-2015-10-7725 and HRZZ-IP-2014-09-2324) and Ministry of Human Capacities. [Hungary grant 20391-3/2018/ FEKUSTRAT].

\section{Appendix A. Supporting information}

Supplementary data associated with this article can be found in the online version at doi:10.1016/j.acthis.2021.151817.

\section{References}

Abed, A.B., Kavvadas, P., Chadjichristos, C.E., 2015. Functional roles of connexins and pannexins in the kidney. Cell. Mol. Life Sci. https://doi.org/10.1007/s00018-0151964-5. 
Adamson, S.E., Meher, A.K., Chiu, Y. hsin, Sandilos, J.K., Oberholtzer, N.P., Walker, N. N., Hargett, S.R., Seaman, S.A., Peirce-Cottler, S.M., Isakson, B.E., McNamara, C.A. Keller, S.R., Harris, T.E., Bayliss, D.A., Leitinger, N., 2015. Pannexin 1 is required for full activation of insulin-stimulated glucose uptake in adipocytes. Mol. Metab. 4, 610-618. https://doi.org/10.1016/j.molmet.2015.06.009.

Alexander, M.P., Patel, T. v, Farag, Y.M.K., Florez, A., Rennke, H.G., Singh, A.K., 2009. Kidney pathological changes in metabolic syndrome: a cross-sectional study. Am. J. Kidney Dis. 53, 751-759. https://doi.org/10.1053/j.ajkd.2009.01.255.

Arifin Wan Nor, Zahiruddin Wan Mohd, 2017. Sample size calculation in animal studies using resource equation approach. Malays. J. Med. Sci. 24. https://doi.org/ 10.21315/mjms2017.24.5.11.

Bretón-Romero, R., Weisbrod, R.M., Feng, B., Holbrook, M., Ko, D., Stathos, M.M., Zhang, J., Fetterman, J.L., Hamburg, N.M., 2018. Liraglutide treatment reduces endothelial endoplasmic reticulum stress and insulin resistance in patients with diabetes mellitus. J. Am. Heart Assoc. 7. https://doi.org/10.1161/ JAHA.118.009379.

de Broe, M.E., Kajbaf, F., Lalau, J.D., 2018. Renoprotective effects of metformin. Nephron. https://doi.org/10.1159/000481951.

Camelliti, P., Devlin, G.P., Matthews, K.G., Kohl, P., Green, C.R., 2004. Spatially and temporally distinct expression of fibroblast connexins after sheep ventricular infarction. Cardiovasc. Res. 62, 415-425. https://doi.org/10.1016/j. cardiores.2004.01.027.

Cataldi, M., Muscogiuri, G., Savastano, S., Barrea, L., Guida, B., Taglialatela, M., Colao, A., 2019. Gender-related issues in the pharmacology of new anti-obesity drugs. Obes. Rev. https://doi.org/10.1111/obr.12805.

Chen, P., Shi, X., Xu, X., Lin, Y., Shao, Z., Wu, R., Huang, L., 2018. Liraglutide ameliorates early renal injury by the activation of renal FoxO1 in a type 2 diabetic kidney disease rat model. Diabetes Res. Clin. Pract. 137, 173-182. https://doi.org/ 10.1016/j.diabres.2017.09.006.

Chiu, Y.H., Schappe, M.S., Desai, B.N., Bayliss, D.A., 2018. Revisiting multimodal activation and channel properties of Pannexin 1. J. Gen. Physiol. 150, 19-39. https://doi.org/10.1085/jgp.201711888.

Cogliati, B., Mennecier, G., Willebrords, J., da Silva, T.C., Maes, M., Pereira, I.V.A., Crespo Yanguas, S., Hernandez-Blazquez, F.J., Dagli, M.L.Z., Vinken, M., 2016 . Connexins, pannexins, and their channels in fibroproliferative diseases. J. Membr. Biol. https://doi.org/10.1007/s00232-016-9881-6.

Cogliati, B., Maes, M., Veloso Alves Pereira, I., Willebrords, J., Da Silva, T.C., Crespo Yanguas, S., Vinken, M., 2016b. Immunohisto- and cytochemistry analysis of connexins. Methods Mol. Biol. 1437, 55-70. https://doi.org/10.1007/978-1-4939. 3664-9_4.

Cui, H., Liu, Y., Qin, L., Wang, L., Huang, Y., 2016. Increased membrane localization of pannexin1 in human corneal synaptosomes causes enhanced stimulated ATP release in chronic diabetes mellitus. Medicine 95, e5084. https://doi.org/10.1097/ MD.0000000000005084.

Diaz-Morales, N., Iannantuoni, F., Escribano-Lopez, I., Bañuls, C., Rovira-Llopis, S., Sola, E., Rocha, M., Hernandez-Mijares, A., Victor, V.M., 2018. Does metformin modulate endoplasmic reticulum stress and autophagy in type 2 diabetic peripheral blood mononuclear cells? Antioxid. Redox Signal. 28. https://doi.org/10.1089/ ars.2017.7409.

Dolmatova, E., Spagnol, G., Boassa, D., Baum, J.R., Keith, K., Ambrosi, C., Kontaridis, M. I., Sorgen, P.L., Sosinsky, G.E., Duffy, H.S., 2012. Cardiomyocyte ATP release through pannexin 1 aids in early fibroblast activation. Am. J. Physiol. Heart Circ. Physiol. 303, 1208-1218. https://doi.org/10.1152/ajpheart.00251.2012.-Fi.

Eckel, R.H., Grundy, S.M., Zimmet, P.Z., 2005. The metabolic syndrome. In: Lancet. Elsevier Limited, pp. 1415-1428. https://doi.org/10.1016/S0140-6736(05)663787.

Felice, J.I., Schurman, L., McCarthy, A.D., Sedlinsky, C., Aguirre, J.I., Cortizo, A.M.,
2017. Effects of fructose-induced metabolic syndrome on rat skeletal cells and tissue, and their responses to metformin treatment. Diabetes Res. Clin. Pract. 126, 202-213. https://doi.org/10.1016/j.diabres.2017.02.011.

Fu, J., Nchambi, K.M., Wu, H., Luo, X., An, X., Liu, D., 2020. Liraglutide protects pancreatic $\beta$ cells from endoplasmic reticulum stress by upregulating MANF to promote autophagy turnover. Life Sci. 252. https://doi.org/10.1016/j lfs.2020.117648.

Gai, Z., Visentin, M., Hiller, C., Krajnc, E., Li, T., Zhen, J., Kullak-Ublick, G.A., 2016. Organic cation transporter 2 overexpression may confer an increased risk of gentamicin-induced nephrotoxicity. Antimicrob. Agents Chemother. 60, 5573-5580. https://doi.org/10.1128/AAC.00907-16.

Geddawy, A., Hussian, M., Kamel, M.Y., Kamal, R., Ibrahim, M.A., 2017. Effects of liraglutide and vitamin $\mathrm{E}$ in fructose-induced metabolic syndrome in rats. Pharmacology 99, 48-56. https://doi.org/10.1159/000449429.

Gewin, L.S., 2018. Renal fibrosis: primacy of the proximal tubule. Matrix Biol. https:// doi.org/10.1016/j.matbio.2018.02.006.

Glastras, S.J., Chen, H., Teh, R., McGrath, R.T., Chen, J., Pollock, C.A., Wong, M.G., Saad, S., 2016. Mouse models of diabetes, obesity and related kidney disease. PLoS One 11, e0162131. https://doi.org/10.1371/journal.pone.0162131.

Haefliger, J.-A., Demotz, P., Braissant, O., Suter, E., Waeber, B., Nicod, P., Meda, P., 2001. Connexins 40 and 43 are differentially regulated within the kidneys of rats with renovascular hypertension. Kidney Int.

Hammer, O., Harper, D., Ryan, P., 2001. PAST: paleontological statistics software package for education and data analysis. Palaeontol. Electron. 4, 1-9.

Hanner, F., von Maltzahn, J., Maxeiner, S., Toma, I., Sipos, A., Krü, O., Willecke, K., PetiPeterdi, J., 2008. Connexin 45 is expressed in the juxtaglomerular apparatus and is involved in the regulation of renin secretion and blood pressure. Am. J. Physiol. Regul. Integr. Comp. Physiol. 295, 371-380. https://doi.org/10.1152/ ajpregu.00468.2007.-Connexin.
Hanner, F., Sorensen, C.M., Holstein-Rathlou, N.-H., Peti-Peterdi, J., 2010. Connexins and the kidney. Am. J. Physiol. Regul. Integr. Comp. Physiol. 298, 1143-1155. https://doi.org/10.1152/ajpregu.00808.2009.-Connexins.

Holderied, A., Romoli, S., Eberhard, J., Konrad, L.A., Devarapu, S.K., Marschner, J.A., Müller, S., Anders, H.J., 2015. Glomerular parietal epithelial cell activation induces collagen secretion and thickening of Bowman's capsule in diabetes. Lab. Investig. 95, 273-282. https://doi.org/10.1038/labinvest.2014.160.

Inyang, K.E., Szabo-Pardi, T., Wentworth, E., McDougal, T.A., Dussor, G., Burton, M.D., Price, T.J., 2019. The antidiabetic drug metformin prevents and reverses neuropathic pain and spinal cord microglial activation in male but not female mice. Pharmacol. Res. 139, 1-16. https://doi.org/10.1016/j.phrs.2018.10.027.

Jurić, M., Zeitler, J., Vukojević, K., Bočina, I., Grobe, M., Kretzschmar, G., SaragaBabić, M., Filipović, N., 2020. Expression of Connexins 37, 43 and 45 in developing human spinal cord and ganglia. Int. J. Mol. Sci. 21, 9356. https://doi.org/10.3390/ ijms 21249356 .

Kanczuga-Koda, L., Sulkowski, S., Koda, M., Sobaniec-Lotowska, M., Sulkowska, M., 2004. Expression of connexins 26, 32 and 43 in the human colon-an immunohistochemical study. Folia Histochem. Cytobiol. 42, 203-207.

Kanczuga-Koda, L., Sulkowski, S., Lenczewski, A., Koda, M., Wincewicz, A., Baltaziak, M., Sulkowska, M., 2006. Increased expression of connexins 26 and 43 in lymph node metastases of breast cancer. J. Clin. Pathol. 59, 429-433. https://doi. org/10.1136/jcp.2005.029272.

Karise, I., Bargut, T.C., del Sol, M., Aguila, M.B., Mandarim-de-Lacerda, C.A., 2019. Metformin enhances mitochondrial biogenesis and thermogenesis in brown adipocytes of mice. Biomed. Pharmacother. 111. https://doi.org/10.1016/j biopha.2019.01.021.

Kawakami, T., Inagi, R., Takano, H., Sato, S., Ingelfinger, J.R., Fujita, T., Nangaku, M., 2009. Endoplasmic reticulum stress induces autophagy in renal proximal tubular cells. Nephrol. Dial. Transplant. 24. https://doi.org/10.1093/ndt/gfp215.

Kim, D., Lee, J.E., Jung, Y.J., Lee, A.S., Lee, S., Park, S.K., Kim, S.H., Park, B.-H., Kim, W., Kang, K.P., 2013. Metformin decreases high-fat diet-induced renal injury by regulating the expression of adipokines and the renal AMP-activated protein kinase/ acetyl-CoA carboxylase pathway in mice. Int. J. Mol. Med. 32. https://doi.org/ 10.3892/ijmm.2013.1508.

Kosovic, I., Filipovic, N., Benzon, B., Bocina, I., Glavina Durdov, M., Vukojevic, K., Saraga, M., Saraga-Babic, M., 2020a. Connexin signaling in the juxtaglomerular apparatus (JGA) of developing, postnatal healthy and nephrotic human kidneys. Int. J. Mol. Sci. 21, 8349. https://doi.org/10.3390/ijms21218349.

Kosovic, I., Filipovic, N., Benzon, B., Vukojevic, K., Saraga, M., Glavina Durdov, M., Bocina, I., Saraga-Babic, M., 2020b. Spatio-temporal patterning of different connexins in developing and postnatal human kidneys and in nephrotic syndrome of the Finnish type (CNF). Sci. Rep. 10, 8756. https://doi.org/10.1038/s41598-02065777-5.

Lazarus, B., Wu, A., Shin, J.I., Sang, Y., Alexander, G.C., Secora, A., Inker, L.A., Coresh, J., Chang, A.R., Grams, M.E., 2018. Association of metformin use with risk of lactic acidosis across the range of kidney function: a community-based cohort study. JAMA Intern. Med. 178, 903-910. https://doi.org/10.1001/ jamainternmed.2018.0292.

Li, Y.K., Ma, D.X., Wang, Z.M., Hu, X.F., Li, S.L., Tian, H.Z., Wang, M.J., Shu, Y.W., Yang, J., 2018. The glucagon-like peptide-1 (GLP-1) analog liraglutide attenuates renal fibrosis. Pharmacol. Res. 131, 102-111. https://doi.org/10.1016/j. phrs.2018.03.004.

Lim, S., Eckel, R.H., 2014. Pharmacological treatment and therapeutic perspectives of metabolic syndrome. Rev. Endocr. Metab. Disord. https://doi.org/10.1007/s11154014-9298-4.

Liu, J., Wei, L., Wang, Z., Song, S., Lin, Z., Zhu, J., Ren, X., Kong, L., 2020. Protective effect of Liraglutide on diabetic retinal neurodegeneration via inhibiting oxidative stress and endoplasmic reticulum stress. Neurochem. Int. 133. https://doi.org/ 10.1016/j.neuint.2019.104624.

Lozić, M., Filipović, N., Jurić, M., Kosović, I., Benzon, B., Šolić, I., Kelam, N., Racetin, A., Watanabe, K., Katsuyama, Y., Ogata, M., Saraga-Babić, M., Vukojević, K., 2021. Alteration of Cx37, Cx40, Cx43, Cx45, Panx1, and renin expression patterns in postnatal kidneys of dab1-/- (yotari) mice. Int. J. Mol. Sci. 22 (1284) https://doi. org/10.3390/ijms22031284.

Luetić, M., Vitlov Uljević, M., Mašek, T., Benzon, B., Vukojević, K., Filipović, N., 2020. PUFAs supplementation affects the renal expression of pannexin 1 and connexins in diabetic kidney of rats. Histochem. Cell Biol. 153. https://doi.org/10.1007/s00418019-01838-9.

Ma, Y. rong, Qin, H. yan, Jin, Y. wen, Huang, J., Han, M., Wang, X. dong, Zhang, G. qiang, Zhou, Y., Rao, Z., Wu, X. an, 2016. Gender-related differences in the expression of organic cation transporter 2 and its role in urinary excretion of metformin in rats. Eur. J. Drug Metab. Pharmacokinet. 41, 559-565. https://doi. org/10.1007/s13318-015-0278-1.

Maric, C., Sandberg, K., Hinojosa-Laborde, C., 2004. Glomerulosclerosis and tubulointerstitial fibrosis are attenuated with 17 beta-estradiol in the aging Dahl salt sensitive rat. J. Am. Soc. Nephrol. JASN 15, 1546-1556. https://doi.org/10.1097/ 01.asn.0000128219.65330.ea.

Mead, R., Gilmour, S.G., Mead, A., 2012. Statistical Principles for the Design of Experiments. Cambridge University Press, Cambridge. https://doi.org/10.1017/ CBO9781139020879.

Narasimhan, A., Chinnaiyan, M., Karundevi, B., 2015. Ferulic acid exerts its antidiabetic effect by modulating insulin-signalling molecules in the liver of high-fat diet and fructose-induced type-2 diabetic adult male rat. Appl. Physiol. Nutr. Metab. Physiol. Appliquée, Nutr. Métabolisme 40, 769-781. https://doi.org/10.1139/apnm-20150002 . 
Nashar, K., Egan, B.M., 2014. Relationship between chronic kidney disease and metabolic syndrome: current perspectives. Diabetes Metab. Syndr. Obes. Targets Ther. https://doi.org/10.2147/DMSO.S45183.

Noyan-Ashraf, M.H., Shikatani, E.A., Schuiki, I., Mukovozov, I., Wu, J., Li, R.K., Volchuk, A., Robinson, L.A., Billia, F., Drucker, D.J., Husain, M., 2013. A glucagonlike peptide- 1 analog reverses the molecular pathology and cardiac dysfunction of a mouse model of obesity. Circulation 127, 74-85. https://doi.org/10.1161/ CIRCULATIONAHA.112.091215.

Ozcan, U., Cao, Q., Yilmaz, E., Lee, A.-H., Iwakoshi, N., Ozcan, E., Tuncman, G., Görgün, C., Glimcher, L., Hotamisligil, G., 2004. Endoplasmic reticulum stress links obesity, insulin action, and type 2 diabetes. Science 306, 457-461. https://doi.org/ 10.1126 /science. 1103160.

Pal, S., Maurya, S.K., Chattopadhyay, S., Pal China, S., Porwal, K., Kulkarni, C., Sanyal, S., Sinha, R.A., Chattopadhyay, N., 2019. The osteogenic effect of liraglutide involves enhanced mitochondrial biogenesis in osteoblasts. Biochem. Pharmacol. 164. https://doi.org/10.1016/j.bcp.2019.03.024.

Panagaki, T., Michael, M., Hölscher, C., 2017. Liraglutide restores chronic ER stress, autophagy impairments and apoptotic signalling in SH-SY5Y cells. Sci. Rep. 7. https://doi.org/10.1038/s41598-017-16488-x.

Park, J.W., Lee, J.H., Park, Y.H., Park, S.J., Cheon, J.H., Kim, W.H., Kim, T.I., 2017. Sexdependent difference in the effect of metformin on colorectal cancer-specific mortality of diabetic colorectal cancer patients. World J. Gastroenterol. 23, 5196-5205. https://doi.org/10.3748/wjg.v23.i28.5196.

Paštar, V., Lozić, M., Kelam, N., Filipović, N., Bernard, B., Katsuyama, Y., Vukojević, K., 2021. Connexin expression is altered in liver development of yotari (dab1 -/-) mice. Int. J. Mol. Sci. 22, 10712. https://doi.org/10.3390/ijms221910712.

Pintana, H., Apaijai, N., Chattipakorn, N., Chattipakorn, S.C., 2013. DPP-4 inhibitors improve cognition and brain mitochondrial function of insulin-resistant rats. J. Endocrinol. 218. https://doi.org/10.1530/JOE-12-0521.

Poudel, N., Okusa, M.D., 2019. Pannexins in acute kidney injury. Nephron. https://doi. org/10.1159/000501278.

Prasad, G.R., 2014. Metabolic syndrome and chronic kidney disease: current status and future directions. World J. Nephrol. 3, 210. https://doi.org/10.5527/wjn.v3.i4.210.

Ren, X., Sun, L., Wei, L., Liu, J., Zhu, J., Yu, Q., Kong, H., Kong, L., 2020. Liraglutide upregulation thioredoxin attenuated Müller cells apoptosis in high glucose by regulating oxidative stress and endoplasmic reticulum stress. Curr. Eye Res. 45. https://doi.org/10.1080/02713683.2020.1737137.

Sa-nguanmoo, P., Tanajak, P., Kerdphoo, S., Jaiwongkam, T., Pratchayasakul, W., Chattipakorn, N., Chattipakorn, S.C., 2017. SGLT2-inhibitor and DPP-4 inhibitor improve brain function via attenuating mitochondrial dysfunction, insulin resistance, inflammation, and apoptosis in HFD-induced obese rats. Toxicol. Appl. Pharmacol. 333. https://doi.org/10.1016/j.taap.2017.08.005.

Saric, M., Masek, T., Filipovic, N., 2017. The Influence of the Tannic Acid on the Expression of the Connexins 45 in a Rat Kidney Damaged by the Chronic Hyperglycemia. ARC J. Diabetes Endocrinol. 3, 11-17. https://doi.org/10.20431/ 2455-5983.0302002.

Sharma, S., Mells, J.E., Fu, P.P., Saxena, N.K., Anania, F.A., 2011. GLP-1 analogs reduce hepatocyte steatosis and improve survival by enhancing the unfolded protein response and promoting macroautophagy. PLoS ONE 6. https://doi.org/10.1371/ journal.pone.0025269.

Singh, A.K., Kari, J.A., 2013. Metabolic syndrome and chronic kidney disease. Curr. Opin. Nephrol. Hypertens. https://doi.org/10.1097/MNH.0b013e32835dda78.

Soldano, S., Montagna, P., Brizzolara, R., Sulli, A., Parodi, A., Seriolo, B., Paolino, S., Villaggio, B., Cutolo, M., 2010. Effects of estrogens on extracellular matrix synthesis in cultures of human normal and scleroderma skin fibroblasts. Ann. N. Y. Acad. Sci. 1193, 25-29. https://doi.org/10.1111/j.1749-6632.2009.05296.x.

Takenaka, T., Inoue, T., Kanno, Y., Okada, H., Meaney, K.R., Hill, C.E., Suzuki, H., 2008. Expression and role of connexins in the rat renal vasculature. Kidney Int. 73, 415-422. https://doi.org/10.1038/sj.ki.5002673.

Tervaert, T.W.C., Mooyaart, A.L., Amann, K., Cohen, A.H., TerenceCook, H., Drachenberg, C.B., Ferrario, F., Fogo, A.B., Haas, M., de Heer, E., Joh, K., Noë, L., Radhakrishnan, L.H., Seshan, J., Bajema, S. v, Bruijn, I.M., J.A, 2010. Pathologic classification of diabetic nephropathy. J. Am. Soc. Nephrol. https://doi.org/ 10.1681/ASN.2010010010.

Torres, L.N., Matera, J.M., Vasconcellos, C.H., Avanzo, J.L., Hernandez-Blazquez, F.J., Dagli, M.L.Z., 2005. Expression of connexins 26 and 43 in canine hyperplastic and neoplastic mammary glands. Vet. Pathol. 42, 633-641. https://doi.org/10.1354/ vp.42-5-633.

Toubas, J., Beck, S., Pageaud, A.-L., Huby, A.-C., Mael-Ainin, M., Dussaule, J.-C., Chatziantoniou, C., Chadjichristos, C.E., 2011. Alteration of connexin expression is an early signal for chronic kidney disease. J. Physiol. Ren. Physiol. 301, 24-32. https://doi.org/10.1152/ajprenal.00255.2010.-Chronic.

Vial, G., Detaille, D., Guigas, B., 2019. Role of mitochondria in the mechanism(s) of action of metformin. Front. Endocrinol. 10. https://doi.org/10.3389/ fendo.2019.00294.

Vitlov Uljević, M., Bočina, I., Restović, I., Kunac, N., Mašek, T., Kretzschmar, G., Grobe, M., Šarić, M., Vukojević, K., Saraga-Babić, M., Filipović, N., 2018. Reabsorption in the proximal tubuli-ultrastructural evidence for a novel aspect of renal VEGF trafficking. Cell Tissue Res. 374. https://doi.org/10.1007/s00441-0182850-x.

Vitlov Uljević, M., Starčević, K., Mašek, T., Bočina, I., Restović, I., Kević, N., Racetin, A., Kretzschmar, G., Grobe, M., Vukojević, K., Saraga-Babić, M., Filipović, N., 2019. Dietary DHA/EPA supplementation ameliorates diabetic nephropathy by protecting from distal tubular cell damage. Cell Tissue Res. 378. https://doi.org/10.1007/ s00441-019-03058-y.

Wang, C., Li, Ling, Liu, S., Liao, G., Li, Lan, Chen, Y., Cheng, J., Lu, Y., Liu, J., 2018. GLP1 receptor agonist ameliorates obesity-induced chronic kidney injury via restoring renal metabolism homeostasis. PLoS ONE 13. https://doi.org/10.1371/journal. pone.0193473.

Wang, G.Y., Bi, Y.G., Liu, X.D., Zhao, Y., Han, J.F., Wei, M., Zhang, Q.Y., 2017. Autophagy was involved in the protective effect of metformin on hyperglycemiainduced cardiomyocyte apoptosis and connexin 43 downregulation in H9c2 cells. Int. J. Med. Sci. 14, 698-704. https://doi.org/10.7150/ijms.19800.

Willebrords, J., Maes, M., Crespo Yanguas, S., Vinken, M., 2017. Inhibitors of connexin and pannexin channels as potential therapeutics. Pharmacol. Ther. 180. https://doi. org/10.1016/j.pharmthera.2017.07.001.

Wu, Y.-C., Wang, W.-T., Lee, S.-S., Kuo, Y.-R., Wang, Y.-C., Yen, S.-J., Lee, M.-Y., Yeh, J.L., 2019. Glucagon-like peptide-1 receptor agonist attenuates autophagy to ameliorate pulmonary arterial hypertension through Drp1/NOX- and Atg-5/Atg-7/ Beclin-1/LC3 $\beta$ pathways. Int. J. Mol. Sci. 20. https://doi.org/10.3390/ ijms20143435.

Yabuki, A., Tahara, T., Taniguchi, K., Matsumoto, M., Suzuki, S., 2006. Neuronal nitric oxide synthase and cyclooxygenase- 2 in diabetic nephropathy of type 2 diabetic OLETF rats. Exp. Anim. 55, 17-25. https://doi.org/10.1159/000348661.

Zhang, S., Xu, H., Yu, X., Wu, Y., Sui, D., 2017. Metformin ameliorates diabetic nephropathy in a rat model of low-dose streptozotocin-induced diabetes. Exp. Ther. Med. 14, 383-390. https://doi.org/10.3892/etm.2017.4475.

Zhang, X., Lerman, L.O., 2017. The metabolic syndrome and chronic kidney disease. Transl. Res. https://doi.org/10.1016/j.trsl.2016.12.004. 